\title{
Design of Uhf Band Microstrip-Fed Antenna for Rfid Applications
}

\author{
Leeza Bansal ${ }^{1}$, Davinder Parkash ${ }^{2}$, Arun $\mathrm{Kumar}^{3}$ \\ 1.M.Tech. Scholar, ECE Deptt., HCTM, Kaithal 136027, India \\ 2.Assoc. Prof. ECE Deptt., HCTM, Kaithal 136027,India \\ 3. $R \&$ D Manager, Omnia Tag Pvt. Ltd., Gurgaon,India
}

\begin{abstract}
In this research work, an UHF band L-shaped antenna based on microstrip-fed is proposed. In this antenna design T-shaped slot is embedded into L-shaped patch. The simulation and design of UHF band antenna operates at resonance frequency $0.897 \mathrm{GHz}$. The proposed antenna is composed of an L-shaped patch embedded with T-shaped slot and covers the UHF RFID band from 0.862-0.925 GHz. The fundamental parameters such as return loss, VSWR, radiation pattern and current distribution are obtained. A parametric study of proposed antenna has been carried out by varying some parameters. Simulation tool, based on method of moments has been used to analyze and optimize the antenna.
\end{abstract}

Keywords: L-shaped Patch, Microstrip line, Radio frequency identification (RFID), Transponders, Ultra High Frequency (UHF).

\section{Introduction}

In general terms, RFID (Radio Frequency Identification) is a means of identifying a person or object using a radio frequency transmission. The technology can be used to identify, track, sort or detect a wide variety of objects. The term RFID refers to Radio Frequency Identification, a technology that uses radio waves to automatically identify items or people [1]. Recently, a lot of research has been done in RFID technology that focused on efficient designs of tags and antenna readers. One of the first applications of a radio frequency identification system was to "Identify Friend or Foe" (IFF) systems used by the British Royal Air Force during World War II to differentiate between German aircraft and their own aircraft through attached radio transponders [2]. It provides wireless identification as well as tracking capability and is more robust than that of barcode. There are many powerful features that make RFID a more effective and efficient in the automatic identification technology [3, 4]. RFID can be used in identifying objects such as in ware housing, supply chain management, and other automation processes. Radio Frequency Identification is based on radio communication for tagging and identifying an object [5]. The main components of a RFID system are tags, readers, and host computer. RFID tags are attached to physical objects so that they can help in identifying objects. An RFID tag consists of a microchip where the information about the object is stored, an antenna connected to the chip, onboard electronics, and a protecting film layer that covers these components [5, 2]. The reader antenna transmits the electromagnetic energy to activate or awaken the tag, realizes the data transfer and sends the instructions to the tag [6]. Meanwhile, the reader antenna receives information from the tag. RFID readers convert the radio waves sent from the tags to get the digital data and send the collected data to the host computer. The present RFID systems are applied at LF (135 kHz), HF (13.56MHz), UHF (860-960) and microwave bands (2.45 \& 5.8 $\mathrm{GHz}$ ) and the antenna design has been focused on these frequency bands [5, 6]. RFID readers can read information stored in no line-of sight.

A dualband antenna RFID tag is presented in [7] that allow operation in the $900 \mathrm{MHz}$ band as well as in the $2.45 \mathrm{GHz}$ band. In [8], a rectangular fractal shaped dual band tag antenna is proposed for RFID which covers entire UHF (860-960 MHz) and microwave (2.45) band. Several papers have been published on RFID antennas for both active and passive tags including novel planar dipole[9], planar antennas for UHF[10] , a novel meandered patch antenna [11], quarter wave Y-shaped patch antenna [12] etc.

In this paper an L-shaped antenna with T-shaped slot is presented which covers UHF band (0.862$0.925 \mathrm{MHz}$ ) which is the operating band of RFID application. The details of the proposed antenna design and the simulated results are presented and discussed next.

\section{Antenna Design}

An L-shaped patch with T-shaped slot is designed for the RFID UHF frequency range and placed on a conventional ground plane. The geometry of the proposed antenna is shown in Fig. 1. The total size of the proposed antenna is $95.5 \times 98 \mathrm{~mm}^{2}$. The antenna mainly constructed with the above described patch and fed by microstrip feeding. The total size of this antenna with ground plane is $113 \mathrm{~mm} \times 100 \mathrm{~mm} \times 1.6 \mathrm{~mm}$. The ground plane is symmetrical at the base line of the feeding strip line. The size of an L-shaped patch is adjusted to obtain 
optimum bandwidth. To obtain the optimal parameters of the proposed antenna for RFID application, IE3D, full-wave commercial EM software that can simulate a finite substrate and a finite ground structure, is used. By properly adjusting the dimension of antenna and feeding structure the characteristics of the proposed antenna is improved. Fig. 1 shows the geometry of proposed antenna and (a) Front view of geometry and (b) Back view of the microstrip patch antenna.
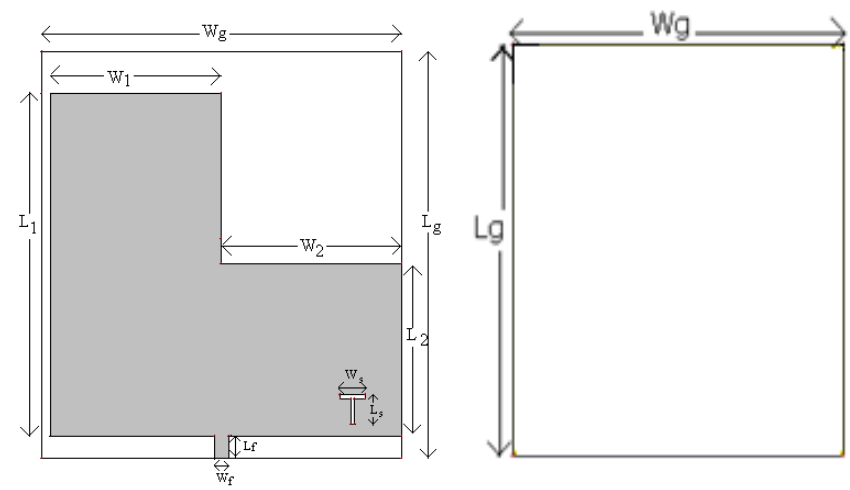

Fig. 1: (a) Front View of proposed UHF band antenna (b) Back View

The optimized dimensions of antenna are set as follows:

Table 1: Parameters of the proposed UHF band antenna

\begin{tabular}{|c|c|}
\hline Parameter & $\begin{array}{c}\text { Dimensions } \\
\text { (in mm) }\end{array}$ \\
\hline $\mathrm{L}_{1}$ & 95.5 \\
\hline $\mathrm{L}_{2}$ & 48 \\
\hline $\mathrm{W}_{1}$ & 48 \\
\hline $\mathrm{W}_{2}$ & 50 \\
\hline $\mathrm{L}_{\mathrm{f}}$ & 6 \\
\hline $\mathrm{W}_{\mathrm{f}}$ & 4 \\
\hline $\mathrm{L}_{\mathrm{g}}$ & 113 \\
\hline $\mathrm{W}_{\mathrm{g}}$ & 100 \\
\hline $\mathrm{L}_{\mathrm{s}}$ & 8 \\
\hline $\mathrm{W}_{\mathrm{s}}$ & 7 \\
\hline
\end{tabular}

The feeding is provided by the rectangular strip of dimensions $6 \times 4 \mathrm{~mm}^{2}$ in the proposed antenna. In an L-shaped patch of antenna, T-shape is embedded as slot. With the aid of simulation by IE3D Simulator which is based on the method of moment (MOM), the antenna is optimized. The details of simulated performance are described briefly in next section.

\section{Simulation Results And Discussions}

The design evolution of the proposed antenna and its corresponding simulated return losses are presented in Fig. 2. It shows the simulated results of the proposed optimized antenna. The UHF band has a -10 $\mathrm{dB}$ impedance bandwidth of $63 \mathrm{MHz}(0.862-0.925 \mathrm{GHz})$ for the simulated results.

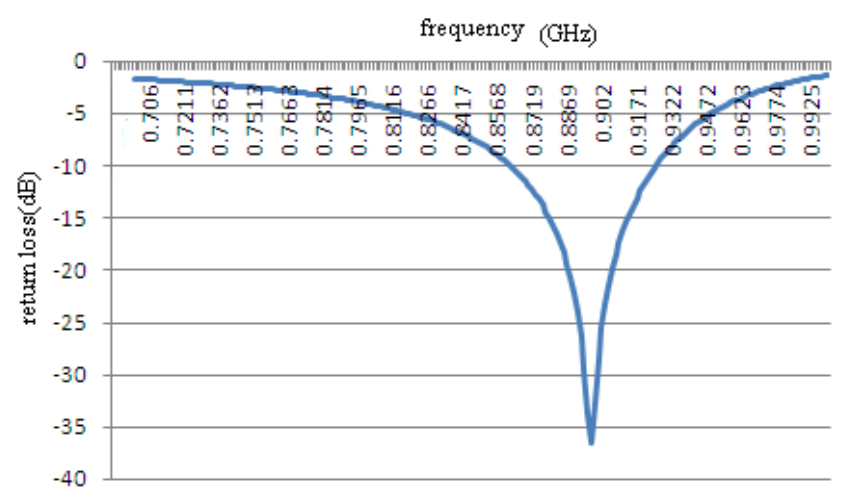

Fig. 2: Return loss of proposed antenna 
It has been examined that proposed design covers the UHF RFID band from 0.862-0.925 GHz. Fig. 3 shows the VSWR of proposed antenna. VSWR of 1.03 is obtained at $0.897 \mathrm{GHz}$.

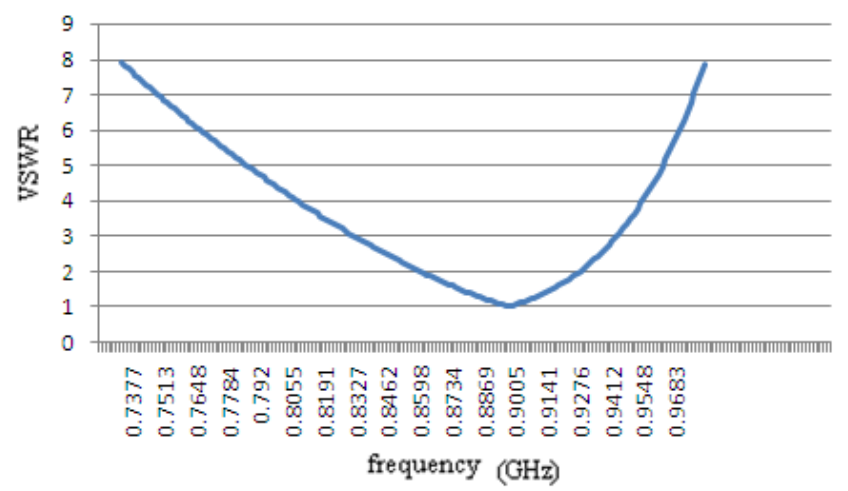

Fig 3: VSWR of proposed antenna versus frequency

Fig. 4 shows the current distribution pattern at $0.897 \mathrm{GHz}$. Maximum current in the proposed antenna is $5.0871(\mathrm{~A} / \mathrm{m})$ at this frequency. The 3D current distribution plot gives the relationship between the copolarization (desired) and cross-polarization (undesired) components. It gives a clear picture as to the nature of polarization of the fields propagating through the patch antenna.

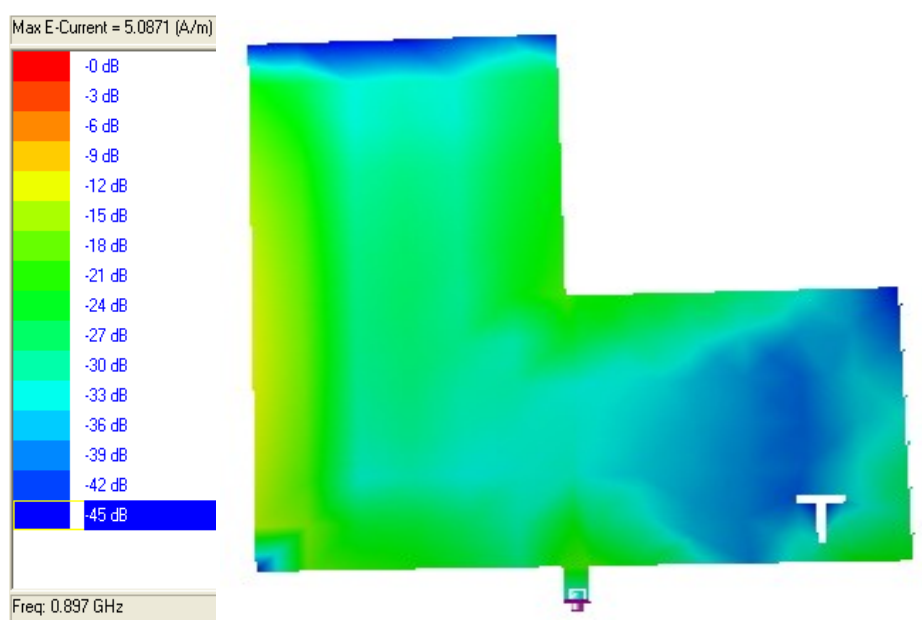

Fig 4: Current Distribution of proposed antenna at $0.897 \mathrm{GHz}$

The simulated 2D radiation pattern for elevation and azimuthal plane at resonant frequency $0.897 \mathrm{GHz}$ is shown in Fig. 5 (a) and (b) respectively. These patterns are desirable for RFID applications. Radiation pattern presents the graphical representation of radiation properties of antenna as a function of space co-ordinates. Three dimensional radiation pattern is obtained by combining elevation pattern and azimuth pattern. Fig. 6 shows three dimensional radiation pattern of proposed antenna.

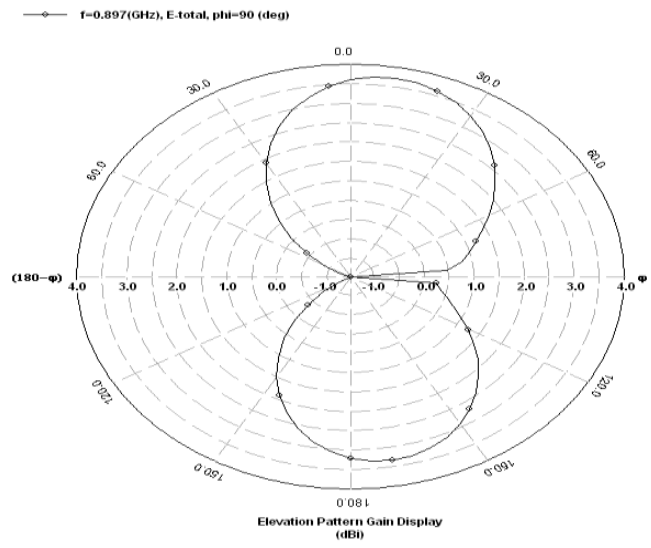

Fig. 5(a): Elevation pattern at $0.897 \mathrm{GHz}$

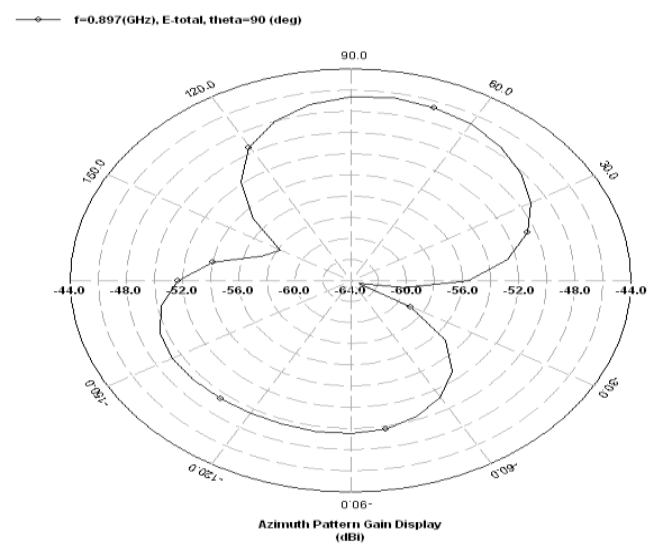

Fig. 5(b): Azimuth pattern at $0.897 \mathrm{GHz}$ 


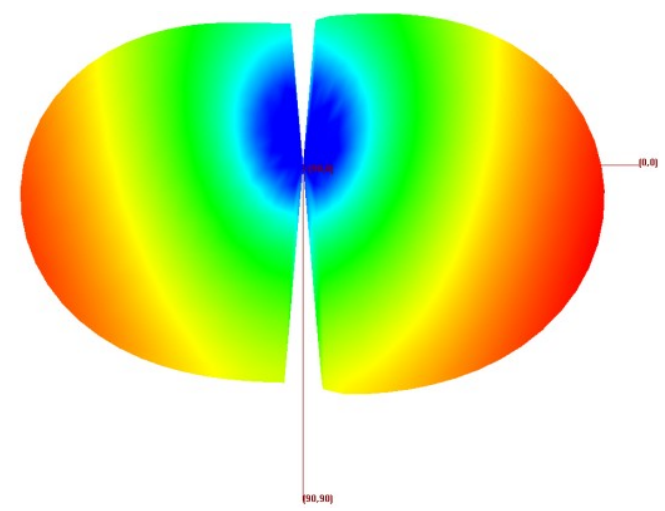

Fig.6: 3-Dimensional Radiation Pattern of Proposed Antenna

\section{Parametric Study}

A parametric study has been carried out and it demonstrates that many parameters affect the performance of the proposed antenna. The parametric study is carried out by simulating the antenna with one geometry parameter slightly changed from the reference design while all the other parameters are fixed.

\subsection{Effect of Embedding T-shaped Slot in Patch:}

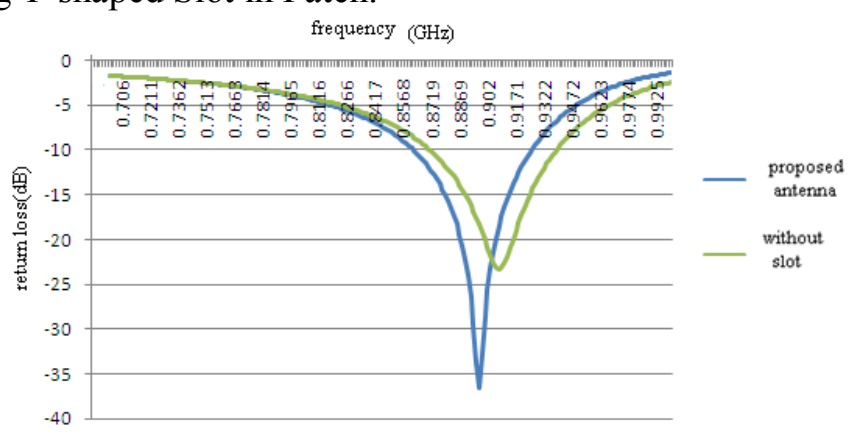

Fig. 7: Parametric Study of Embedding Slots

Fig. 7 shows antenna performance is improved by adding slot in patch. Firstly, primitive antenna is taken without any slot, and then antenna is embedded with T-shaped slot. Then, we observe that as we add slot to the patch, the impedance bandwidth as well as frequency band coverage is improved.

4.2 Effect of Variation of ' $W$ ' on Antenna Performance:

Fig.8 showing the case when width of patch changed, there was no impedance bandwidth in working bands. The variation of width has a greater effect on the antenna performance. It can be seen, as we increase ' $\mathrm{W}$ ' from optimized value, the return loss in $\mathrm{dB}(-\mathrm{ve})$ will decrease and as if we decrease ' $\mathrm{W}$ ' from optimized value, the return losses will also decrease. Thus the variation of ' $\mathrm{W}$ ' has a greater effect on the antenna performance.

4.3 Effect of Variation of ' $\mathrm{L}_{\mathrm{f}}$ ' on Antenna Performance:

Fig. 9 showing the case when $\mathrm{L}_{\mathrm{f}}$ slightly changed from the reference design, then the return losses in $\mathrm{dB}(-\mathrm{ve})$ will decrease. It can be seen, as we increase or decrease $\mathrm{L}_{\mathrm{f}}$, the return loss in $\mathrm{dB}(-\mathrm{ve})$ will decrease.

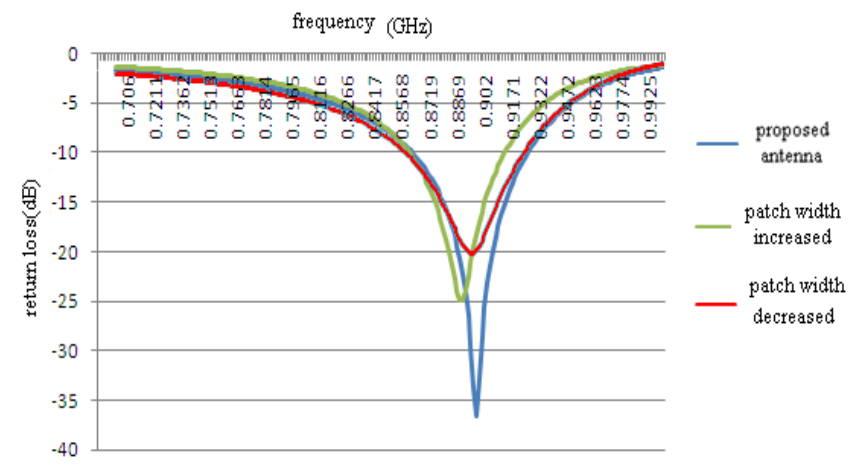

Fig.8: Return loss (S11) of the antenna for different values of W. 


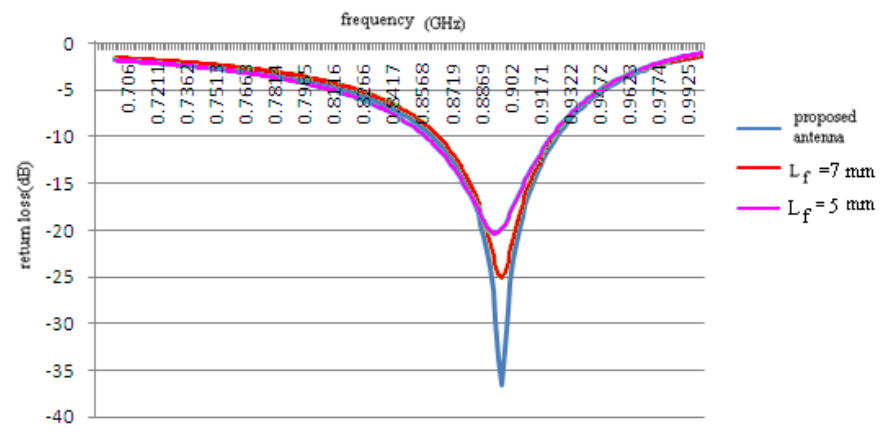

Fig.9: Return loss (S11) of the antenna for different values of $\mathrm{L}_{\mathrm{f}}$.

\section{Conclusion}

A design of UHF-band microstrip fed antenna for RFID tag applications has been proposed. It covers UHF RFID band from 0.862-0.925 GHz. A dual band operation has been obtained and good radiation characteristics have been observed at $0.897 \mathrm{GHz}$. The proposed antenna has been designed and simulated for resonant frequency at $0.897 \mathrm{GHz}$. Effects of varying dimensions of key structure parameters on the antenna and various parameters like VSWR, current distribution, radiation pattern and their performance are also studied. These characteristics are very attractive for some wireless communication systems for a variety of applications.

[1] www.extronics.com/intro-to-rfid.

\section{References}

[2] http://www.eecs.harvard.edu/cs199r/readings/rfid-article.pdf.

[3] http://www.ferroxcube.com/appl/info/RFID introduction.pdf.

[4] eprints.rclis.org/16848/2/RFID-SECURITY-Bibhuti.ppt.

[5] eprints.ibu.edu.ba/1058/1/vol1-no1-p53-71.pdf

[6] Ming-Tao Zhang, Yong-Chang Jiao, Fu-Shun Zhang and Wu-Tu Wang, Design of antennas for RFID application, February 2009,Available from http://www.intechopen.com.

[7] Tran Minh Tuan, Design dual band microstrip antenna for RFID application, VNU Journal of Science, Natural Sciences and Technology 26 (2010) 276-280.

[8] Yi-Chieh Lee and Jwo-Shiun Sun, Dual-band dipole antenna for RFID tag applications, Proceedings of the 38th European Microwave Conference.

[9] G. Monti, L. Catarinucci, and L. Tarricone, Broad-Band Dipole for RFID applications, Progress In Electromagnetics Research C, Vol. 12, 163-172, 2010.

[10] Arun Kumar, Davinder Parkash, and M. V. Kartikeyan, Planar antennas for passive UHF RFID tags, Progress In Electromagnetics Research B, Vol. 19, 305-327, 2010.

[11] Jyoti Ranjan Panda, Aditya Sri Ram Saladi, Rakhesh Singh Kshetrimayum, A compact printed monopole antenna for dual-band RFID and WLAN applications, Radio Engineering, Vol. 20, No. 2, June 2011.

[12] Kelechi Hilary Anabi, J. S. Mandeep, M. Islam and J. J. Tiang, A quarter-wave Y-shaped patch antenna with two unequal arms for wideband Ultra High Frequency Radio-frequency identification (UHF RFID) operations, International Journal of the Physical Sciences Vol. 6(26), pp. 6200-6209, 30 October, 2011. 